\title{
Fungal Degradation of the Bioplastic PHB (Poly-3-hydroxy- butyric acid)
}

\author{
K.-M. Lee, ${ }^{1,2,3}$ D. F. Gimore, ${ }^{1}$ and M. J. Huss ${ }^{1}$
}

Correction: The second

author's name is Gilmore, not

Gimore.

\begin{abstract}
PHB (poly-3-hydroxybutyric acid) is a thermoplastic polyester synthesized by Ralstonia eutropha and other bacteria as a form of intracellular carbon and energy storage and accumulated as inclusions in the cytoplasm of these bacteria. The degradation of PHB by fungi from samples collected from various environments was studied. PHB depolymerization was tested in vials containing a PHB-containing medium which were inoculated with isolates from the samples. The degradation activity was detected by the formation of a clear zone below and around the fungal colony. In total, 105 fungi were isolated from 15 natural habitats and 8 lichens, among which 41 strains showed PHB degradation. Most of these were deuteromycetes (fungi imperfecti) resembling species of Penicillium and Aspergillus and were isolated mostly from soils, compost, hay, and lichens. Soil-containing environments were the habitats from which the largest number of fungal PHB degraders were found. Other organisms involved in PHB degradation were observed. A total number of 31 bacterial strains out of 67 isolates showed clear zones on assay medium. Protozoa, possible PHB degraders, were also found in several samples such as pond, soil, hay, horse dung, and lichen. Lichen, a fungi and algae symbiosis, was an unexpected sample from which fungal and bacterial PHB degraders were isolated.
\end{abstract}

KEY WORDS: PHB; fungi; biodegradation.

\section{INTRODUCTION}

The possibility of increasing environmental pollution and exhaustion of non-renewable fossil resources have encouraged research on biosynthetic and biodegradable materials [1]. Polyhydroxyalkanoates (PHAs), naturally-occurring polyesters of various hydroxyalkanoates, are synthesized by a very broad range of microorganisms as intracellular inclusions of carbon and energy reserve compounds under unbalanced growth conditions [2]. PHA

\footnotetext{
${ }^{1}$ Environmental Sciences Program, Arkansas State Unversity, AR 72467, USA.

2 Manager/R\&D Center Celltrion, Inc., 1001-5 Dongchun-dong Yeonsu-gu, Inchen 406-130, Korea.

3 To whom all correspondence should be addressed. E-mail: klee0922@yahoo.co.kr
}

is now being produced industrially by several companies over the world for use as natural, biodegradable, and biocompatible thermoplastics with a variety of potential applications [3].

Poly-3-hydroxybutyrate (PHB) is the most well known member of the family of PHAs [4]. PHB is similar to polypropylene in its physical properties, but has the advantage of being biodegradable $[2,5]$. PHB has been shown to be completely biodegraded by bacteria into water and carbon dioxide (and methane under anaerobic conditions) in natural environments, including water, soil, and compost [6].

According to the literature, fungal participation in PHB degradation has so far only been shown under certain environmental conditions [7-12]. However, fungi may be involved in the primary degradation of PHB due to their dominant ability 
to decompose organic matter. The lack of data regarding the ability of fungi to degrade PHB and their potential role in degrading PHB in various natural environments prompted this study.

Using a basal culture medium made turbid by the addition of PHB inclusions, a clear zone test was used to screen fungal isolates from a variety of habitats for PHB-degrading enzyme activities. The occurrence of clear zones on a turbid plate or vial indicates the degradation of polymer particles to soluble molecules due to enzyme activity arising from the PHB degrader.

A correlation between the normal ecological role of fungi and the possession of PHB-degrading ability of different microorganisms was characterized and noted in this study. The purpose of this project was to acquire knowledge of PHA-degrading organisms, their distribution among specific ecosystems, and clarification of the relationship between the habitat and the degradation activity. These data will be helpful for elucidating the role of fungi in the bacterial plastic (PHB) degradation process and predicting the involvement of fungi in the degradation of PHB should it be discarded and enter the environment as a manufactured item such as plastic bag, bottle, and other litter.

\section{EXPERIMENTAL}

\section{Microorganisms Used}

The strain used in PHB production was Ralstonia eutropha (obtained from University of Massachusetts at Amherst). Cephalosporium sp. (A.S.U. fungal culture collection) and Aspergillus fumigatus (T3A, S. Goodwin, University of Massachusetts at Amherst; [12]) were used as positive controls in tests to identify PHB degraders. These two genera are known to grow on the surface of the assay medium and show clear zones within a week [13].

\section{PHB Synthesis and Extraction}

$R$. eutropha was incubated in a two stage culture system. Stage 1 medium contained $1 \%$ peptone, $1 \%$ yeast extract, and $0.5 \% \mathrm{NH}_{4} \mathrm{SO}_{4}$. After growth $(48 \mathrm{~h})$, cells were collected by centrifugation and transferred to $600 \mathrm{ml}$ of stage 2 medium, mineral salts medium, $\mathrm{pH} 6.5$, fed with a total of $0.06 \mathrm{ml} \mathrm{mol}$ of butyric acid in $\mathrm{pH} 6.5$ phosphate over $36 \mathrm{~h} \mathrm{[14].}$
Two solutions were used for extraction of PHB from cells [14]. To destroy the cells and free the PHB inclusions, an alkaline detergent solution consisting of $1 \%$ Triton $\mathrm{X}-100$ in $0.1 \mathrm{~N} \mathrm{NaOH}(\mathrm{pH} \mathrm{13)}$ was used. Cell debris was further solubilized by treatment of crude PHB with a solution of $15 \%(\mathrm{w} / \mathrm{v})$ sodium carbonate in bleach (5.25\% sodium hypochlorite). PHB confirmation and concentration were conducted by gas chromatography after methanolysis [15].

\section{Culture Media}

Tryptic soy agar (TSA) and Saboraud dextrose agar $(\mathrm{SAB})$ were used for the routine maintenance of fungal cultures. A dilute SAB (1/10 SAB) was used in the isolation of fungi from many environmental samples. Media used to enrich and screen for PHB-degrading organisms are shown in Table I. The basal medium consisted of numerous mineral

Table I. Screening and Enrichment Culture Media

\begin{tabular}{|c|}
\hline Basal medium \\
\hline 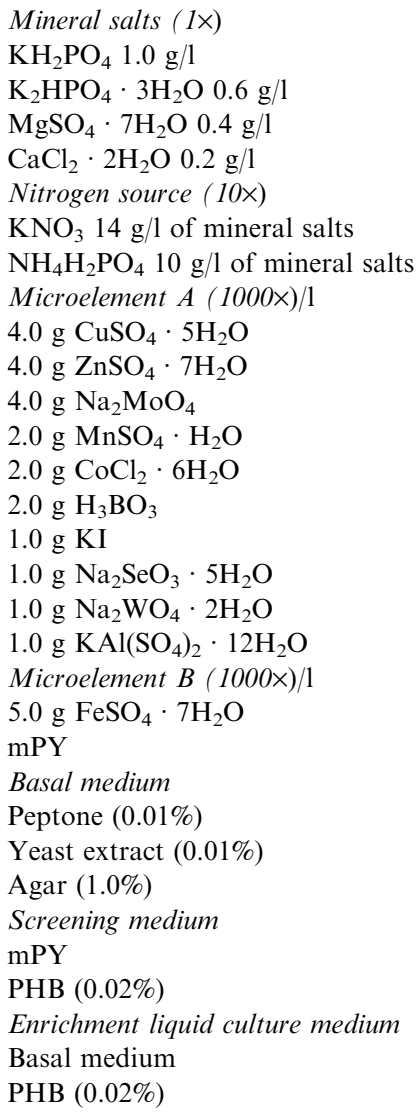 \\
\hline
\end{tabular}

All media were adjusted to $\mathrm{pH} 6.0$. 
salts [1]. Basal medium supplemented with $0.01 \%$ peptone and $0.01 \%$ yeast extract (mPY), containing $0.066 \mathrm{~g}$ wet PHB inclusions (about $0.02 \mathrm{~g}$ of dry PHB), and solidified with $1.0 \%$ agar was used to screen for PHB degradation. All enrichment and screening media were adjusted to $\mathrm{pH}$ 6.0.

Assay medium $(10 \mathrm{ml})$ was pipetted into each vial (standard $20 \mathrm{ml}$ scintillation vial). For bacterial degradation, plates containing $20 \mathrm{ml}$ of assay medium were prepared. Liquid enrichment culture medium used to enrich for PHB-degrading fungi from homogenized lichen thalli consisted of $25 \mathrm{ml}$ of basal medium containing PHB (0.02\%) (no peptone or yeast extract).

\section{Preparation of $1 / 10 \times$ Sabouraud Dextrose Agar (SAB) Plate}

Diluted SAB plates $(1 / 10 \times)$ were prepared using $0.3 \mathrm{~g}$ Sabouraud dextrose agar plus $1.35 \mathrm{~g}$ agar (Difco) per $100 \mathrm{ml}$ of distilled water $(1.5 \%$ final concentration of agar). The $\mathrm{pH}$ was adjusted to 6.0 before autoclaving. All tubings, glassware, and media were sterilized by autoclaving at $121{ }^{\circ} \mathrm{C}$ at 15-20 psi for $15 \mathrm{~min}$.

\section{Samples from Environments}

Twenty four samples from various natural habitats including eight lichens (from A.S.U. campus and Jonesboro, AR area) were taken to study the degradation capabilities of fungi from different ecosystems. Soil compost was home-made, consisting of garden soils and leaves, and hay compost was laboratory-made, composed of dry farm hay with regular watering for three months. Air sample was collected from laboratory window with an open SAB medium plate and an assay vial. Leaf samples were selected based on their different physical states. Cotton boll, farm soil, farm hay, and horse dung were collected from a private farm near the A.S.U campus. Each collected sample was inoculated into a vial $(20 \mathrm{ml})$ containing assay medium to test for the presence of PHB-degrading organisms by checking for clear zones. Subsequently, individual species were isolated from the raw samples as described below.

\section{Isolation of Fungi}

Most collected samples were suspended by vortexing in $10 \mathrm{ml}$ of sterilized distilled water and allowed to stand for several minutes. The supernatants were then serially diluted. A portion of supernatant $(0.1 \mathrm{ml})$ from each dilution was transferred to a $1 / 10 \times \mathrm{SAB}$ plate to culture. For samples hard to mix with water such as leaves, inocula were taken directly from the surface of the samples with a sterilized swab. After 2-3 days incubation, fungal colonies containing a few hyphae and bacterial colonies, if any, were picked up and cultivated at $30^{\circ} \mathrm{C}$ on a SAB or TSA slant, respectively, for a week for further growth.

\section{Lichen Culture Preparation}

The cleansing of lichen was followed by fungal isolation and incubation. First, collected lichen thalli were suspended with sterile distilled water as described above. This procedure was repeated in order to remove as much surface contamination such as dust and dirt particles as possible. Then, fragments of thallus bearing small fruiting bodies were taken and transferred into a autoclaved homogenizer. After homogenizing the thallus with $10 \mathrm{ml}$ sterilized distilled water, one loopful of suspension was streaked onto $1 / 10 \times \mathrm{SAB}$ plates and inoculated into the liquid enrichment culture medium. The plates were held at $18^{\circ} \mathrm{C}$, because lichen has been known to grow well at the relatively low temperature of $15^{\circ} \mathrm{C}$ [16]. The enriched liquid culture was incubated in the shaker and transferred to a $1 / 10 \times \mathrm{SAB}$ plate. Fungal isolation and screening tests were the same as for other samples.

\section{Inoculation and Incubation}

A small piece from an isolated fungal culture on a slant was inoculated into a test vial containing assay medium. The vials was held in an incubator at $28^{\circ} \mathrm{C}$ and checked visually for degradation every day. The plate-puncture technique was conducted for detecting bacterial degradation on a plate. This technique was carried out by first dipping a sterile loop or needle into a bacterial colony, then pushing the implement into the agar of a PHB-containing assay plate, puncturing the agar [17]. The inoculated plates were treated the same as test vials. A control was incubated in parallel.

\section{Determination of PHB Degradation}

PHB degradation was determined by checking the depth of the clear zone in test vials and the 
diameter in plates. Also, the time was measured for the initial appearance of clear zones. Since some fungi grow slowly and show enzyme activity late, determination of $\mathrm{PHB}$ degradation required an incubation time of 8 weeks [1]. This test is qualitative, and the formation of clear zones around and beneath colonies on agar or the complete degradation of PHB in the assay medium are endpoints for this assay.

\section{Classification of the Isolated Organisms}

PHB-degrading fungi were catagorized into four types by morphology, texture, color, and shape of mycelial mass, and by examination of hyphal structure, spores, sporangia, and other cellular structures using a light microscope.

Table II. Samples Tested

\begin{tabular}{|c|c|c|}
\hline Samples & $\begin{array}{l}\text { PHB } \\
\text { Degradation } \\
\text { (clear zone } \\
\text { formation) }\end{array}$ & $\begin{array}{l}\text { Initial } \\
\text { appearance } \\
\text { of clear } \\
\text { zone (days) }\end{array}$ \\
\hline \multicolumn{3}{|l|}{ Positive control } \\
\hline T3A & + & 2 \\
\hline Cephalosporium sp. & + & 2 \\
\hline \multicolumn{3}{|l|}{ Environments ${ }^{\mathrm{a}}$} \\
\hline Soil compost & + & 10 \\
\hline Hay compost & + & 20 \\
\hline Garden soil & + & 10 \\
\hline Air & + & 17 \\
\hline Cotton boll & + & 13 \\
\hline Fallen leaf & + & 25 \\
\hline Living leaf & + & 39 \\
\hline Rotten leaf & + & 7 \\
\hline Plant root & + & 7 \\
\hline Farm soil & + & 2 \\
\hline Farm hay & + & 2 \\
\hline Pond & + & 2 \\
\hline Horse dung & + & 2 \\
\hline Ceiling pipe & + & 12 \\
\hline Shower stall/ bathtub & + & 30 \\
\hline Human skin & - & \\
\hline \multicolumn{3}{|l|}{ Wild mushroom $^{\mathrm{a}}$} \\
\hline Wood rotter & - & \\
\hline \multicolumn{3}{|l|}{ (Aphyllophorales) } \\
\hline Gilled mushrooms & - & \\
\hline (Agricales) & & \\
\hline
\end{tabular}

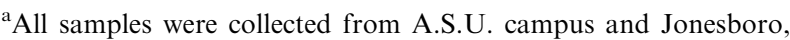
AR area.

${ }^{\mathrm{b}}$ The number of days between inoculation and the first appearance of a clear zone.

\section{RESULTS}

\section{Sample Collection}

Samples were collected from 16 different ecological niches and other specific places. Most raw samples inoculated into assay medium showed clear zones (Table II) indicating that PHB-degrading microorganisms are present in most environments.

\section{Isolation of Fungi and Bacteria}

Diluted samples incubated on $1 / 10 \times$ SAB plates produced a variety of fungal and bacterial colonies after 2-3 days of incubation. Every distinct colony was transferred to a SAB (fungi) or TSA (bacteria) slant in order to obtain the maximum number of potential PHB-degrading organisms. These should not be considered independent isolates since they were collected from the same plates. A total of 62 fungal strains were obtained (Table III). Protozoal cysts were observed on the plates inoculated with farm hay, pond sediment, farm soil, and horse dung plates, but no attempt were made to isolate them for screening.

\section{PHB Degradation Test of the Isolates}

A small piece of fungal culture from each slant was transferred into an assay vial. After 1-3 weeks of incubation (depending on isolate), a clear zone formed around and beneath the inoculum. The clear zones in the vials varied in depth and clarity, suggesting differences in metabolic states of the PHB-degrading isolates, diffusion rates of different enzymes in medium, and the amounts and activities of the enzymes $[1,17]$.

A total of 26 isolated fungal strains out of 62 showed clear zones around and below their inoculum sites (Table III). The largest number of fungal degrader was observed, in order from soil compost, soils, and farm hay, with 8, 7, and 5 isolates, respectively. Fungi were not isolated from pond water by this method. This result was consistent with one from Mergaert et al. [18]. A total number of 13 bacterial strains out of 35 isolates also showed clear zones on a plate assay medium (data not shown). Although bacteria are known to be major PHBdegrading organisms, relatively few were isolated because the culture conditions intentionally favored the growth of fungi. These bacteria were not studied further. 
Table III. PHB Degradation by Fungal Isolates

\begin{tabular}{|c|c|c|c|c|}
\hline Environments & Isolates & Type $^{\mathrm{a}}$ & Degradation & $\begin{array}{l}\text { Time } \\
\text { (days) }\end{array}$ \\
\hline \multirow[t]{9}{*}{ Soil compost } & $\# 1$ & Type I & + & 4 \\
\hline & $\# 2$ & Type I & + & 4 \\
\hline & $\# 3$ & Type I & + & 4 \\
\hline & \# 4 & Type I & + & 4 \\
\hline & $\# 5$ & Type I & + & 6 \\
\hline & \# 6 & Type I & + & 4 \\
\hline & $\# 7$ & Type I & + & 5 \\
\hline & $\# 8$ & Type III & - & \\
\hline & $\# 9$ & Type III & + & 10 \\
\hline \multirow[t]{6}{*}{ Hay compost } & \# 1 & Type III & - & \\
\hline & $\# 2$ & Type III & - & \\
\hline & $\# 3$ & Type III & - & \\
\hline & $\# 4$ & Type III & - & \\
\hline & $\# 5$ & Type III & - & \\
\hline & \#6 & Type III & - & \\
\hline \multirow[t]{12}{*}{ Garden soil } & \# 1 & Type I & + & 7 \\
\hline & $\# 2$ & Type I & + & 5 \\
\hline & $\# 3$ & Type I & + & 18 \\
\hline & $\# 4$ & Type I & + & 18 \\
\hline & $\# 5$ & Type I & + & 18 \\
\hline & $\# 6$ & Type I & - & \\
\hline & \# 7 & Type I & - & \\
\hline & $\# 8$ & Type I & - & \\
\hline & \# 9 & Type I & - & \\
\hline & \# 10 & Type I & - & \\
\hline & \# 11 & Type I & - & \\
\hline & $\# 12$ & Type II & + & 5 \\
\hline \multirow[t]{7}{*}{ Air } & \# 1 & Type IV & + & 5 \\
\hline & $\# 2$ & Type IV & + & 5 \\
\hline & \# 3 & Type II & - & \\
\hline & $\# 4$ & Type I & - & \\
\hline & \# 5 & Type I & - & \\
\hline & $\# 6$ & Type I & - & \\
\hline & $\# 7$ & Type I & - & \\
\hline \multirow[t]{4}{*}{ Cotton boll } & $\# 1$ & Type I & + & 3 \\
\hline & $\# 2$ & Type I & - & \\
\hline & $\# 3$ & Type I & - & \\
\hline & $\# 4$ & Type I & - & \\
\hline \multirow[t]{3}{*}{ Fallen leaf } & $\# 1$ & Type I & - & \\
\hline & $\# 2$ & Type I & - & \\
\hline & $\# 3$ & Type I & - & \\
\hline Rotten leaf & $\# 1$ & Type I & - & \\
\hline \multirow[t]{3}{*}{ Living leaf } & $\# 1$ & Type III & + & 8 \\
\hline & $\# 2$ & Type III & - & \\
\hline & $\# 3$ & Type I & - & \\
\hline Plant root & \# 1 & Type III & + & 7 \\
\hline \multirow[t]{5}{*}{ Farm soil } & \# 1 & Type I & + & 3 \\
\hline & $\# 2$ & Type I & - & \\
\hline & $\# 3$ & Type III & - & \\
\hline & $\# 4$ & Type III & - & \\
\hline & $\# 5$ & Type III & - & \\
\hline \multirow[t]{6}{*}{ Farm hay } & $\# 1$ & Type III & + & 2 \\
\hline & $\# 2$ & Type III & + & 7 \\
\hline & \#3 & Type III & + & 9 \\
\hline & $\# 4$ & Type III & + & 4 \\
\hline & $\# 5$ & Type I & + & 4 \\
\hline & $\# 6$ & Type I & - & \\
\hline
\end{tabular}

Table III. Continued

\begin{tabular}{lclll}
\hline Environments & Isolates & Type $^{\mathrm{a}}$ & Degradation & $\begin{array}{c}\text { Time } \\
\text { (days) }\end{array}$ \\
\hline Pond & $\begin{array}{l}\text { No mold } \\
\text { isolated }\end{array}$ & & & \\
Horse dung & $\# 1$ & Type III & - & \\
Ceiling pipe & $\# 1$ & Type I & + & 12 \\
& $\# 2$ & Type I & - & \\
\multirow{2}{*}{ Shower stall/bathtub } & $\# 3$ & Type I & - & \\
& $\# 1$ & Type III & - & \\
\hline
\end{tabular}

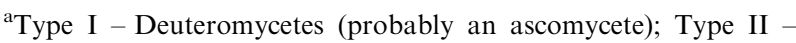
Deuteromycetes (probably a basidiomycete); Type III - zygomycetes; Type IV - Yeast.

\section{Lichen and PHB Degradation}

Seven out of eight lichens tested showed positive reactions, showing definite clear zones within a week (Table IV). This prompted further study of PHB degradation by lichens. A total of 43 fungal strains, representing all major types of filamentous fungi, were isolated from 7 lichens; 15 of these strains showed PHB degradation (Table V).

In addition to fungi, many different bacterial colonies grew on the $1 / 10 \times$ SAB plates. Several of these colonies consisted of thin hyphae and appeared to be actinomycetes, but these isolates were not further identified. Actinomycetes, as well as other bacteria, have been reported as principle components of lichen thalli [19]. Of the 32 bacterial isolates from $1 / 10 \times \mathrm{SAB}$ plates, 18 strains tested positive for PHB degradation in plate assays.

During liquid enrichment culture of homogenized lichen thalli, motile ciliates were observed. These microbes could be seen darting in and out of clumps of PHB. It is not clear whether they were specifically attracted to and feeding on PHB granules or other microbes using the PHB as a nutrient source.

\section{DISCUSSION}

During initial experiments, the PHB-degradation screening assay was optimized. Among the adjustments were decrease of PHB used from 0.1 to $0.02 \%$ (to more easily visualize clear zones), decrease of agar concentration from 1.5 to $1.0 \%$ (improved penetration of fungal hyphae), and use of screw cap vials instead of culture tubes or Petri dishes (improved surface area and less contamination). 
Table IV. Collected Lichen Samples

\begin{tabular}{llcc}
\hline Environments $^{\mathrm{a}}$ & Group & PHB-degradation & Time (days) \\
\hline Fallen branch & Crustose 1 & + & 2 \\
& Crustose 2 & + & 2 \\
\multirow{5}{*}{ Bark of tree } & Crustose 3 & + & 5 \\
& Foliose 1 & + & 2 \\
& Foliose 2 & + & 3 \\
& Foliose 3 & + & 7 \\
& Crustose 1 & + & \\
\hline
\end{tabular}

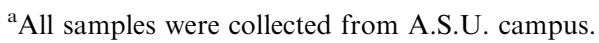

Prior to studying environmental samples, a fungal culture collection containing 48 strains from many genera were screened for PHB degradation. However, only one strain, a Cephalosporium sp. showed any degradation, despite the presence of Penicillium and Aspergillus species in the collection, genera known to be PHB degraders. We hypothesize that these strains, of indeterminate age, are likely to have lost any PHA-degrading ability during repeated subculturing. We then sought environmental samples, looking for any correlations between the finding of PHB-degrading fungi and the likelihood of PHB-producers being present in that environment.

All the environments sampled showed evidence of PHB degraders. This is predictable, in view of the biodiversity of polymer-producing prokaryotes in these environments [20] and the consequent availability of PHB as a nutrient source. It appears likely that PHB-containing bacteria become nonviable or are victims of predation, leading to the availability of this nutrient source and ecological success for microbes that can use it. Fungi that degrade PHB were mostly isolated from soil, compost, and farm hay, environments in which large quantities of bacteria thrive. These fungi were predominantly Deuteromycetes, possibly Ascomycetes, a finding consistent with the results of Mergaert et al. [21]. Only one fungal degrader was tentatively identified as a basidiomycete, in contrast to the results on Matavulj and Molitoris [1] who found the highest percentage of BIOPOL (poly-3-hydroxybutyrate-co-hydroxyvalerate) degradation among the Basidiomycete group using the same medium (mPY). It seems to be due to either different type of PHAs or different sample collections.

To our knowledge, this is the first report of PHB degradation by lichens. When a small piece of crustose lichen thallus tested positive for
Table V. PHB Degradation by Fungi Isolated From Lichens

\begin{tabular}{|c|c|c|c|c|}
\hline Lichen & Isolates & Type $^{\mathrm{a}}$ & Degradation & $\begin{array}{l}\text { Time } \\
\text { (days) }\end{array}$ \\
\hline \multirow[t]{7}{*}{ Branch crustose 1} & \# 1 & Type I & + & 8 \\
\hline & $\# 2$ & Type I & + & 2 \\
\hline & \# 3 & Type I & + & 10 \\
\hline & \# 4 & Type I & + & 3 \\
\hline & $\# 5$ & Type I & + & 3 \\
\hline & $\# 6$ & Type I & - & \\
\hline & \# 7 & Type III & - & \\
\hline \multirow[t]{7}{*}{ Branch crustose 2} & $\# 1$ & Type I & + & 5 \\
\hline & $\# 2$ & Type I & + & 5 \\
\hline & \# 3 & Type I & + & 3 \\
\hline & $\# 4$ & Type I & + & 3 \\
\hline & $\# 5$ & Type I & - & \\
\hline & \# 6 & Type I & - & \\
\hline & \# 7 & Type I & - & \\
\hline \multirow[t]{2}{*}{ Branch crustose 3} & $\# 1$ & Type I & - & \\
\hline & $\# 2$ & Type I & + & 3 \\
\hline \multirow[t]{3}{*}{ Bark foliose 1} & $\# 1$ & Type II & - & \\
\hline & $\# 2$ & Type II & - & \\
\hline & $\# 3$ & Type I & - & \\
\hline \multirow[t]{12}{*}{ Bark foliose 2} & $\# 1$ & Type I & - & \\
\hline & $\# 2$ & Type I & - & \\
\hline & $\# 3$ & Unidentified & - & \\
\hline & $\# 4$ & Type I & - & \\
\hline & \# 5 & Type I & - & \\
\hline & \# 6 & Type I & - & \\
\hline & $\# 7$ & Type I & - & \\
\hline & $\# 8$ & Type I & - & \\
\hline & \# 9 & Unidentified & - & \\
\hline & $\# 10$ & Type I & - & \\
\hline & \# 11 & Type I & + & 3 \\
\hline & \# 12 & Type I & + & 3 \\
\hline \multirow[t]{8}{*}{ Bark foliose 3} & $\# 1$ & Type I & - & \\
\hline & $\# 2$ & Type I & - & \\
\hline & \# 3 & Type I & - & \\
\hline & $\# 4$ & Type I & + & 4 \\
\hline & $\# 5$ & Type I & + & 4 \\
\hline & \# 6 & Type I & - & \\
\hline & \# 7 & Type I & - & \\
\hline & $\# 8$ & Type I & + & 3 \\
\hline \multirow[t]{4}{*}{ Bark crustose 1} & $\# 1$ & Type I & - & \\
\hline & $\# 2$ & Type I & - & \\
\hline & \# 3 & Unidentified & - & \\
\hline & $\# 4$ & Type III & - & \\
\hline
\end{tabular}

${ }^{\mathrm{a}}$ Type I - Deuteromycetes (probably an ascomycete); Type II Deuteromycetes (probably a basidiomycete); Type III - zygomycetes; Type IV - Yeast.

degradation, several lichens were collected and studied more closely. Lichens are small ecosystems unto themselves, with the phycobiont responsible for fixing carbon, the mycobiont obtaining other nutrient from the surrounding, and a variety of bacteria, fungi, and protozoa participating in the local nutrient cycling [27-30]. An effort was made to isolate 
fungi associated with, and responsible for, the lichen symbiosis. Several fungi were isolated which could possibly be mycobionts. The morphology of these fungal colonies was unique; on solid medium, the hyphae mixed together forming a dense, mycelial mass at the surface and penetrated deeply into the agar medium. The tendency to penetrate is characteristic of a mycobiont because penetration of the fungus into the algal photobiont is required during lichen formation [22, 23]. The conglutinate, spherical colonies (3-5 $\mathrm{mm}$ in diameter) formed on the surface of $1 / 10 \times \mathrm{SAB}$ resembled a clump or lobe of lichen tissue. However, no PHB degradability was detected from these isolates. Most PHB degraders considered to be lichenicolous fungi, which are secondary fungi inhabiting or associated with lichens [24-26].

Several environmental samples showed PHB degradation but failed to yield any isolates with PHB-degrading activity. These included compost, pond water, horse dung, shower stall/bath, and two lichens. Three explanations are possible for this result. The degrading microbe may have been a bacterium that was not isolated under the culture conditions used or simply not tested as a pure culture. It is also possible that a fungus capable of degrading PHB resisted isolation attempts. Finally, significant degradation may have only occurred through the action of a mixed culture which was dismantled by the act of isolation [12].

\section{CONCLUSIONS}

Fungi isolated from a variety of environmental samples were capable of PHB degradation. This is consistent with their role in nature as organic polymer degraders. Samples yielding the greatest proportion of fungal isolates of different morphologies were compost, garden soil, and hay. These samples were likely to contain the greatest bacterial diversity, and thus more likely to contain PHB and more likely to support the existence of PHB-degrading fungi.

Another, less expected source of PHB-degrading fungi was lichen. In retrospect, it should not be surprising that lichen would be a source of PHBdegrading organisms. Nutritional condition in lichens are high in carbon (through photosynthesis) and low in other nutrients, conditions that promote bacterial synthesis of PHB. It would follow that lichen-associated organisms would include PHB degraders. It would be interesting to identify the specific lichen-associated bacteria involved in PHB synthesis as a first step in following perturbations in carbon flow in lichens, an organisms negatively impacted by air pollution.

\section{REFERENCES}

1. M. Matavulj, and H. P. Molitoris (1992) FEMS Microbiol. Rev. 103, 323-331.

2. S. Y. Lee (1996b) Trends Biotechnol. 14, 431-438.

3. V. C. Kalia, N. Raizada, and V. Sonakya (2000) J. Sci. Indust. Res.. 59, 433-445.

4. W. J. Page (1995) Can. J. Microbiol. 41(Suppl. 1), 1-3.

5. H. Brandl, and P. Puchner (1992) Biodegradation. 2, 237-243.

6. G. Swift (1993) Acc. Chem. Res. 26, 105-110.

7. D. Y. Kim, and Y. H. Rhee (2003) Appl. Microbiol. Biotechnol. 61, 300-308.

8. B.-I Sang, K. Hori, Y. Tanji, and H. Unno (2002) Appl. Microbiol. Biotechnol. 58, 241-247.

9. K. E. Gonda, D. Jendrossek, and H. P. Molitoris (2000) Hydrobiologia. 426, 173-183.

10. M.-N. Kim, A.-R. Lee, J.-S. Yoon, and I.-J. Chin (2000c) Eur. Polym. J. 36, 1677-1685.

11. J. Mergaert, and S. J. Swing (1996) J. Indust. Microbiol. 17, 463-469.

12. D. F. Gilmore, S. Antoun, R. W. Lenz, S. Goodwin, and R. Austin (1992) J. Indust. Microbiol. 10, 119-206.

13. H. Brandl, R. Bachofen, J. Mayer, and E. Wintermantel (1995) Can. J. Microbiol. 41(Suppl. 1), 143-153.

14. I. A. Ramsay, E. Berger, B. A. Ramsay, and C. Chavarie (1990) Biotechnol. Tech. 4, 221-226.

15. H. Brandl, R. A. Gross, R. W. Lenz, and R. C. Fuller (1988) Appl. Environ. Microbiol. 54, 1977-1982.

16. V. Ahmadjian (1993) The Lichen Symbiosis, John Wiley \& Sons Inc., New York.

17. J. Augusta, R. J. Muller, and J. Widdecke (1993) Appl. Microbiol. Biotechnol. 39, 673-678.

18. J. Mergaert, A. Webb, C. Anderson, A. Wouters, and S. J. Swing (1993) Appl. Environ. Microbiol. 59, 3233-3238.

19. P. D. Crittenden, J. C. David, D. L. Hawksworth, and F. S. Cambell (1995) New Phytol. 130, 267-297.

20. H. Brandl, R. A. Gross, R. W. Lenz, and R. C. Fuller (1990) Adv. Biochem. Eng. Biotechnol. 41, 77-93.

21. J. Mergaert, G. Gorieus, L. Hauben, V. Storms, M. Mau, and J. Swings (1996) Syst. Appl. Microbiol. 19, 407-413.

22. R. Honegger (1991) Аnnu. Rev. Plant Physiol. Plant Mol. Biol. 42, 553-578.

23. R. Honegger (1993) New Phytol. 125, 659-677.

24. J. D. Lawrey (1995) Rev. Can. J. Bot. 73 (Suppl. 1), s603s608.

25. O. Petrini, U. Hake, and M. M. Dreyfuss (1990) Mycologia 82, 444-451.

26. D. L. Hawksworth (1982) J. Hattori Bot. Lab. 52, 377-366.

27. C. J. Alexooulos, C. W. Mims, and M. Blackwell (1996) Introductory Mycology, 4th ed. John Wiley \& Sons Inc., New York, pp. 382-391

28. T. D. Brock, M. T. Madigan, J. M. Martinko, and J. Parker (1994) Biology of Microorganisms, 7th ed. Prentice Hall, Upper Saddle River, New Jersey, pp. 648-650.

29. P. D. Crittenden, and N. Porter (1991) Tibtech. 9, 409-414.

30. A. C. Palmisano, and C. A. Pettigrew (1992) Bioscience. 42, 680-685. 